\title{
Stages of change model has limited value in explaining the change in use of cannabis among adolescent participants in an efficacious motivational interviewing intervention
}

Citation for published version (APA):

Dupont, H. B., Candel, M. J. J. M., Lemmens, P., Kaplan, C., van de Mheen, D., \& de Vries, N. K. (2017). Stages of change model has limited value in explaining the change in use of cannabis among adolescent participants in an efficacious motivational interviewing intervention. Journal of Psychoactive Drugs, 49(5), 363-372. https://doi.org/10.1080/02791072.2017.1325030

Document status and date:

Published: 01/01/2017

DOI:

10.1080/02791072.2017.1325030

Document Version:

Publisher's PDF, also known as Version of record

Document license:

Taverne

Please check the document version of this publication:

- A submitted manuscript is the version of the article upon submission and before peer-review. There can be important differences between the submitted version and the official published version of record. People interested in the research are advised to contact the author for the final version of the publication, or visit the DOI to the publisher's website.

- The final author version and the galley proof are versions of the publication after peer review.

- The final published version features the final layout of the paper including the volume, issue and page numbers.

Link to publication

\footnotetext{
General rights rights.

- You may freely distribute the URL identifying the publication in the public portal. please follow below link for the End User Agreement:

www.umlib.nl/taverne-license

Take down policy

If you believe that this document breaches copyright please contact us at:

repository@maastrichtuniversity.nl

providing details and we will investigate your claim.
}

Copyright and moral rights for the publications made accessible in the public portal are retained by the authors and/or other copyright owners and it is a condition of accessing publications that users recognise and abide by the legal requirements associated with these

- Users may download and print one copy of any publication from the public portal for the purpose of private study or research.

- You may not further distribute the material or use it for any profit-making activity or commercial gain

If the publication is distributed under the terms of Article 25fa of the Dutch Copyright Act, indicated by the "Taverne" license above,

Download date: 26 Apr. 2023 


\section{Journal of Psychoactive Drugs}

\section{Stages of Change Model has Limited Value in Explaining the Change in Use of Cannabis among Adolescent Participants in an Efficacious Motivational Interviewing Intervention}

Hans B. Dupont, Math J. J. M. Candel, Paul Lemmens, Charles D. Kaplan, Dike van de Mheen \& Nanne K. De Vries

To cite this article: Hans B. Dupont, Math J. J. M. Candel, Paul Lemmens, Charles D. Kaplan, Dike van de Mheen \& Nanne K. De Vries (2017) Stages of Change Model has Limited Value in Explaining the Change in Use of Cannabis among Adolescent Participants in an Efficacious Motivational Interviewing Intervention, Journal of Psychoactive Drugs, 49:5, 363-372, DOI: 10.1080/02791072.2017.1325030

To link to this article: https://doi.org/10.1080/02791072.2017.1325030

Published online: 26 May 2017.

Ц Article views: 585

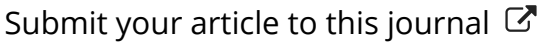




\title{
Stages of Change Model has Limited Value in Explaining the Change in Use of Cannabis among Adolescent Participants in an Efficacious Motivational Interviewing Intervention
}

\author{
Hans B. Dupont, Ph.D. a,b, Math J. J. M. Candel, Ph.D. , Paul Lemmens, Ph.D.c, Charles D. Kaplan, Ph.D.d, \\ Dike van de Mheen, Ph.D. ${ }^{\mathrm{e}, \mathrm{g}}$, and Nanne K. De Vries, Ph.D. ${ }^{\mathrm{h}}$
}

\begin{abstract}
aMoti-4 Research Project Coordinator, CAPHRI, School for Public Health and Primary Care, Maastricht University, Maastricht, the Netherlands; ${ }^{b}$ Manager, Addiction Prevention Department, Mondriaan, Heerlen, the Netherlands; 'Professor, Statistical Department, CAPHRI, School for Public Health and Primary Care, Maastricht University, Maastricht, the Netherlands; ${ }^{d}$ Assistant Professor, CAPHRI, School for Public Health

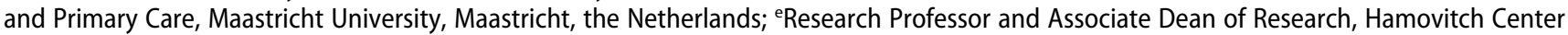

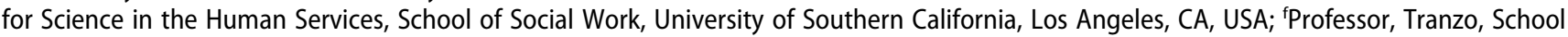
of Social and Behavioral Sciences, Tilburg University, Tilburg, the Netherlands; ${ }^{9}$ Manager, Addiction Research Institute, Rotterdam, the Netherlands; ' Dean, CAPHRI, School for Public Health and Primary Care, Maastricht University, Maastricht, the Netherlands
\end{abstract}

\begin{abstract}
Previously, a Dutch randomized controlled trial evaluating an intervention aimed at changing adolescents' cannabis use, called Moti-4, has shown its efficacy. A secondary analysis of the Moti-4 data investigated the process of change specified by the Stage of Change (SOC) model in cannabis use during the trial. Seventy-one Moti-4 participants and 60 controls were recruited for the study with a pre-test, post-test (T1), and six-month follow-up (T2). All participants showed signs of problematic cannabis use. No contribution of the Moti-4 intervention to a change in SOC between T1 and T2 was found. Although motivation for treatment and motivation for change can be conceived as independent predictors of treatment outcome, the SOC a person is in does not mediate the effect of the intervention on change in cannabis use. However, a reduction in cannabis use was associated with a positive change in "action willingness," in line with the SOC model. In contrast to model expectations, a higher score on "contemplation" is associated with a higher cannabis consumption. Results highlight both the limitations and usefulness of the SOC model. Future interventions may focus more on the stage of "action willingness," as well as on perceived social norms.
\end{abstract}

\section{ARTICLE HISTORY}

Received 7 June 2016

Revised 21 March 2017

Accepted 27 March 2017

\section{KEYWORDS}

Cannabis; motivational interviewing; stages of change model; targeted prevention; transtheoretical model
Compared to its use in other European countries, cannabis use in the Dutch general population is of average prevalence (Degenhardt and Hall, 2012; EMCDDA 2014; Van Laar et al. 2015). Cannabis use among Dutch adolescents, however, is higher than in most other European Union countries (Hibell et al. 2012), with a prevalence of use of $14 \%$ in the past month among adolescents aged 15 to 16 years, compared to 7\% Europe-wide. While most adolescent consumers use cannabis without negative consequences, some users experience problems related to frequent use (Van Laar et al. 2015). Cannabis use is associated with a variety of psychosocial and health problems, including cognitive and respiratory impairment, low educational achievement, psychotic episodes, and dependence (Copeland and Swift 2009; Hall and Solowij 1998; Horwood et al. 2010; Kuepper et al. 2011; Snoek, Wits, and Van Der
Stel 2010). Since it is predominantly adolescents (1324) who use (non-medical) cannabis, public health workers should specifically focus on adolescent and young adult populations when designing effective interventions.

Motivational Interviewing (MI) is a client-centered counseling style that aims to explore and resolve ambivalence about changing behaviors (De Jonge 2005; Miller and Rollnick 2012). Brief MI interventions have been developed (Barnett et al. 2012; De Gee et al. 2014; Martin and Copeland 2008); however, little research has explored the efficacy and effectiveness of such interventions when targeting alcohol and drug use among adolescents. Randomized controlled studies of MI have shown mixed results (Apodaca and Longabough 2009). The most consistent evidence was found for the effects of the intervention elements of change talk, intention, 
MI-consistent behavior of the therapist, client's experience of discrepancy, and the use of the decisional balance (Miller and Rollnick 2012). To our knowledge, no studies have investigated the mechanisms of change that could account for the efficacy of MI-based interventions among adolescent problematic cannabis users.

The Stages of Change (SOC) model, also known as the Transtheoretical Model (TTM) of behavior change, was developed by Prochaska and DiClemente (1984) more than three decades ago. This model of behavior change assesses a person's readiness to change to healthier behavior. It provides strategies or processes of change to guide the individual through the stages of change, starting from the stage of Precontemplation through the stages of Contemplation, Decision to Action, and Maintenance. Stages of change, processes of change, self-efficacy, decisional balance, and temptations are important constructs.

The lack of conclusive scientific evidence has stimulated widespread criticism of the SOC model in recent years (Etter and Sutton 2002; Riemsma et al. 2002; Van Sluis, Van Poppel, and Van Mechelen 2004; Quinlan and McCaul 2000; West 2005). Researchers have claimed that the evidence for the model as applied to addictive behaviors is meager (Sutton 2001); others even have advocated dropping the model entirely (West 2005). There is also robust evidence that the SOC model is not a valid stage model when applied to other areas than addictive behaviors (De Vet 2005). Despite the lack of evidence, the model is still popular and continues to be applied by developers of interventions in tobacco, alcohol, and drug prevention (Apodaca and Longabough 2009; Evers et al. 2012; Migneault, Adams, and Read 2005; Sussman et al. 2011), who appreciate its logical structure and heuristic value (Schippers 2009). In addition, reliable and valid scales for measuring SOC are available, which create confidence in the applicability of the concepts in the SOC model (Napper et al. 2008).

Motivation for change is fundamental to understanding the process of reducing drug use, as evidenced by the widespread use of MI in drug abuse prevention and treatment cited earlier. Recently, a randomized controlled trial of the Australian Adolescent Cannabis Check Up (ACCU), involving a two-session brief motivational enhancement (Martin and Copeland 2008), has been replicated in the Netherlands. The results could not be replicated (De Gee et al. 2014). In a review article, $67 \%$ of the studies were found to report beneficial effects of brief motivational enhancement (Barnett et al. 2012). In this same study, all seven studies on cannabis interventions showed significant reductions in use. These results could indicate that motivational enhancement is especially appropriate in interventions aimed at reducing levels of cannabis use.

Related to this accumulating evidence is recent Dutch research of substance-dependent patients with co-occurring psychiatric disorders (De Weert-Van Oene et al. 2015). In this research, "motivation for treatment" was analytically distinguished from "motivation for change." The association between these constructs has been investigated in studies on alcohol treatment (Lau et al. 2010), but similar studies on drug-abusing populations are scarce. The current study examined whether this theoretical distinction can be upheld in a sample of Dutch youth whose cannabis use is deemed problematic in a secondary analysis of stage of change data drawn from a randomized clinical trial (RCT) assessing the efficacy of a MI intervention designed to reduce the use of cannabis.

The efficacy trial measured participants' stage of change at pre- and post-test, and at a six-month follow-up, using the validated Dutch version of Readiness for Change Questionnaire (RCQ), the same instrument used in the Dutch substance-dependent patient study (Defuentes-Merillas, De Jong, and Schippers 2002). In the RCT, Moti- 4 participants decreased their cannabis use, as measured in money spent and number of joints consumed per week, significantly more than controls (Dupont et al. 2015a).

The first aim of the secondary analysis of the RCT data was to investigate whether the Moti-4 intervention affects motivation for change as distinguished from motivation to engage in the treatment, compared to a control group. That is, the Moti-4 participant group should be significantly different than the control group in their stages of change from pre-contemplation through contemplation to direct action, as described in the SOC theory. The second aim of the current study was to evaluate whether the change in cannabis use resulting from the Moti-4 intervention follows the pathway suggested by the SOC model; in essence, whether change in SOC stage mediates the effect of the Moti- 4 intervention on the reduced use of cannabis.

\section{The Moti-4 intervention}

Intervention Mapping (Bartholomew et al. 2011), a systematic approach to developing theory- and evidence-based interventions, was used to develop the protocol for Moti-4 (Dupont et al. 2015b). The goal of Moti- 4 is to stimulate adolescents to critically examine and adjust their own drug use. Moti-4 consists of several modules, spread over four sessions, in which the adolescent talks to a trained prevention worker. In 
the first session, an inventory is made of the participant's substance use, severity of use problems, psychiatric or physical problems, and relevant school or family issues. This is followed by sessions with a focus on knowledge transfer, creating awareness, motivational interviewing, and strengthening resilience. If the prevention worker ascertains that the adolescent has a severe substance abuse disorder, the participant will be referred to treatment as soon as possible.

The Moti-4 protocol consists of 14 mandatory modules: assessment of use and life areas, stage of use, recording use/diary, users chart, knowledge transfer, reasons for use, pros and cons, self-confidence, social network, peer pressure and craving, designing a plan for change, giving feedback to the person who did the referral, meeting with parents or educators (optional), and planning of the follow-up (Dupont et al. 2015b). The modules' content is based on the Theory of Planned Behavior (Fishbein and Ajzen 2010), Motivational Interviewing (Miller and Rollnick 2012), the SOC Model (Prochaska and DiClemente 1984), SelfMonitoring (Rooke et al. 2013), and Self-Determination Theory (Ryan and Deci 2000). The Theory of Planned Behavior postulates that intention, as the most important determinant of behavior, is itself conditioned by three independent constructs: attitude, subjective norms, and perceived behavioral control (self-efficacy). Knowledge (beliefs) of the effects of cannabis and dependence form the basis for change. During the sessions, problem awareness (evaluation) is raised, and behavior resilience and engagement in behavioral alternatives are encouraged (self-efficacy). Discussing the social norms of the adolescents' environment is expected to change behavioral intention. The theoretical basis of Moti-4 also includes Self-Determination Theory. During the intervention, the conditions supporting the individual experiences of autonomy, competence, and relatedness are discussed. These aspects are thought to affect motivation for change most strongly.

\section{Methods}

\section{Participants and design}

Moti-4 is designed for adolescents and young adults (aged 14-24 years) currently using cannabis (past month). Participants also met one or more of the following inclusion criteria:

(1) A clear relationship between cannabis intake and problems at school, at work or in relationships (Henry 2010; Pope et al. 2003), as reported by parents, teachers, or other referrers.

(2) Experiencing physical or mental health problems (Kuepper et al. 2011; Van Os, Kenis, and Rutten 2010), as reported by parents, teachers, or other referrers.

(3) Being at high risk of developing problematic use because of personal circumstances, such as homelessness or marginalization, truancy, having addicted parents, and attending special education (Snoek, Wits, and Van Der Stel 2010; Van Laar et al. 2015).

(4) Age-inappropriate experimentation (Madras et al. 2009).

Twenty-seven professionals recruited 168 youth, 37 of whom did not enroll after contact. Participants were referred to the prevention worker by their parents, by agencies for youth care and drop-out, by prevention field workers, and by student counsellors in the school system. Of the 131 who did enroll, 71 were randomized to the intervention condition and 60 to the control condition. The control condition consisted of one hour of protocolized knowledge transfer. A computerized animation was used to illustrate the information. In this control condition, the participants' knowledge about cannabis and its effects was challenged in a quiz at the end of the session. The answers were discussed and an information leaflet was given to the youth to take home. Prevention workers were instructed to avoid MI techniques such as open-ended questioning and directed reflecting. Personal advice was only given at explicit request. A small number of participants dropped out after one session (remaining: $n=124$ ) or after six months (remaining: $n=114$ ). A medical ethics committee (METC Atrium:12N 110) approved the study and all participants signed informed consent before participation. Pre- and post-test (T0 and T1) and follow-up assessments after six months (T2) were conducted with intervention as well as control group members.

\section{Measurement instruments}

The primary outcome measure was the quantity of cannabis use, assessed by asking the respondent to estimate the amount of money spent each week. If respondents were growing cannabis themselves or getting it for free, they were asked to give a reliable estimate. In total, seven questions on cannabis, alcohol, and other drug use were asked. The psychosocial determinants of cannabis use were based on the I-Change model (De Vries et al. 1995), which can 
be regarded as an adaptation of the Theory of Planned Behavior (Fishbein and Ajzen 2010). All of these determinants were assessed with items having five-point Likert answer scales $(1=$ totally agree, $5=$ totally disagree), which were later merged into one variable for each determinant. Attitude was measured with eight items, four of which were about the pros (social, relaxed, happy, creative) and four about the cons (bad for your lungs, expensive, negative influence on school performance, and development of mental disorder) of cannabis use. Perceived behavioral control was assessed by two items (How difficult is it for you not to smoke cannabis? How difficult is it for you to refuse a joint when a friend offers you one?). Social influence was assessed by three questions concerning friends and their cannabis use (How many of your friends are cannabis users? How often do you hang out with users? How often do you hang out with non-users?), four questions on social norms (both approval and disapproval of friends and parents, respectively), and one question on perceived peer pressure (How often do you experience pressure from your friends to smoke a joint?). Three intentions were measured: the intention to use cannabis, the intention to quit, and the intention to reduce cannabis consumption. Action plans were measured by three questions (I made specific plans to: stop, reduce, and resist, respectively).

Stage of change according to the SOC model was assessed at T0, T1, and T2 using the Readiness for Change Questionnaire (RCQ) (Heather, Rollnick, and Bell 1993; Rollnick et al. 1992). Heather, Rollnick, and Bell (1993) defined the stage of change that a person is in by means of an algorithm in which the categorical stage of change is determined by the highest score on any of the three subscales of the RCQ. In the case of a tie (an even score), the stage farther along the continuum of change is chosen. The analyses also considered the mean scores on the RCQ subscales representing each of the stages of change. These scores are regarded as reflecting the extent to which the participant endorsed that particular stage of change (Rollnick et al. 1992). The validated Dutch version used in this study includes three subscales, with four items each, corresponding to the stages of pre-contemplation (P), contemplation (C), and action (A) (Defuentes-Merillas, De Jong, and Schippers 2002). Participants scored their response on a Likert-type scale from 1 (Strongly disagree) to 5 (Strongly agree). If the score on one of the items of a subscale was missing, the average of the remaining item scores was calculated as the subscale score. In other instances, the subscale score was coded missing.

\section{Statistical analysis}

Criticisms have been leveled at the RCQ scoring procedure (West 2005), which may obfuscate individual variation in the scoring profiles on the subscales. Before determining the stage of each individual, it was therefore ascertained whether the scoring pattern on RCQ subscales and the correlations between RCQ subscales were in line with the theoretical expectations of a progressive change from the pre-contemplation stage, through contemplation, to the action stage (i.e., a construct validity test). Partial correlations were calculated between different subscale scores at different times, controlling for intervention group membership. If the postulated progression through stages took place, one would expect a negative (partial) correlation between the pre-contemplation scores and action scores (Heather, Rollnick, and Bell 1993; McConnoughy et al. 1983; Rollnick et al. 1992).

Scores on pre-contemplation, contemplation, and action were calculated for $\mathrm{T} 0, \mathrm{~T} 1$, and $\mathrm{T} 2$, and subsequently used to define the stage of change at T0, T1, and T2. Next, the stage changes from T0 to T1 and from $\mathrm{T} 0$ to $\mathrm{T} 2$ were calculated, simply as the difference scores for the stages, with the pre-contemplation stage being coded as 1 , the contemplation stage as 2 , and the action stage as 3 .

Top-down multiple linear regression analyses (Field 2009; Kleinbaum, Kupper, and Muller 1988) were performed to assess the impact of the intervention on the likelihood of having a positive change of stage at T1 and at $\mathrm{T} 2$, as determined by the direction and significance of the regression coefficients. Since the variable change in the SOC stage was not normally distributed, and the sample size was relatively small, bootstrapping was employed to determine $p$-values and bias-corrected confidence intervals for the regression coefficients. The number of bootstrap samples was 5000. In the next step, top-down multiple linear regressions were again conducted to examine whether the changes in the motivational stage immediately after the intervention and after six months were predictors of the change in cannabis use. All regression analyses used a top-down strategy to remove some of the covariates; i.e., gender; age; education; nationality; living situation; baseline cannabis use; baseline use of tobacco, alcohol, and other drugs; baseline attitude; social norm; and perceived behavioral control. These covariates were used when testing for the effect of Moti-4 on stage of change, and additionally Moti-4 participation, when testing for 
the effect of stage of change on cannabis use. These covariates allowed for the correction of the effect of either Moti- 4 or the effect of change in stage of change for possible confounding variables (Dupont et al. 2015a). At each step, the least significant covariate was excluded and these control variables were removed until only variables with a significance level of .10 or smaller remained. Finally, to examine whether the change in stage was a mediator of the effect of the Moti-4 intervention as found previously, the results from both top-down regressions were combined in the joint significance test of mediation (MacKinnon et al. 2002). That is, if there is a significant effect of Moti- 4 on stage change, and stage change in turn has a significant effect on change in cannabis use, we can declare stage of change a mediator. To complement the earlier analyses involving changes in the stage of change, top-down multiple linear regressions were performed, ignoring the change to another stage, but examining the ability of Moti- 4 to change the RCQ scores for the pre-contemplation, contemplation, and action stages directly after the intervention and after six months. Subsequently, top-down multiple linear regressions were used to evaluate the influence of the change in these scores on cannabis use at $\mathrm{T} 1$ and $\mathrm{T} 2$.

\section{Results}

At baseline, no statistically significant differences between conditions were found regarding sex, age, the institution where the participant was recruited, their education, living situation, cannabis use, use of alcohol and other drugs, or attitude, social norm, and perceived behavioral control (Table 1). Only the alcohol intake differed significantly between the groups. Furthermore, none of these variables had a statistically significant relationship with the dropout rate at either T1 or T2.

As the test of construct validity, the partial correlation analysis between subscale scores of the RCQ at different time points indicated by the negative correlations between the $\mathrm{P}$-subscale and the $\mathrm{C}$ - and A-subscales were in line with the theoretical expectations. Moderate positive correlations were found for the $\mathrm{C}$ - and A-subscales at $\mathrm{T} 1$ and $\mathrm{T} 2$, indicating a progressive change from a stage of pre-contemplation, through contemplation, to action. The use of the aforementioned cut-off algorithm (Heather, Rollnick, and Bell 1993), which determines the stage that a person is in, resulted in an overall increase in the numbers allocated to the action stage and a decrease in the percentage in the pre-contemplation and contemplation stages over time. These results are also in line with the theory. We found no significant differences between the Moti-4 intervention and control groups. A stable percentage of around $17 \%$ remained in the P-stage over the course of the study, while an accelerating decline in percentages at the C-stage from $40 \%$ to $24 \%$ and a corresponding accelerating increase in the percentages in the A-stage from $43 \%$ to $61 \%$ were evident.

The results of the top-down multiple regressions were used to assess the impact of Moti- 4 on favorable change in stage (Table 2). Thirteen variables were included as covariates. Neither at T1 nor at T2 was a significant effect of Moti-4 found. Also, none of the other predictors made a significant contribution at $\mathrm{T} 1$. At T2, gender, social norm, cannabis and alcohol consumption at $\mathrm{T} 0$ made significant contributions to a positive change in stage. At $\mathrm{T} 1$, the final model

Table 1. Sample characteristics at baseline.

\begin{tabular}{|c|c|c|c|c|}
\hline & $\begin{array}{c}\text { Total Sample } \\
(n=131)\end{array}$ & $\begin{array}{c}\text { Moti-4 condition } \\
\quad(n=71)\end{array}$ & $\begin{array}{l}\text { Control condition } \\
\quad(n=60)\end{array}$ & \multirow[b]{2}{*}{ Statistical test value } \\
\hline & \multicolumn{3}{|c|}{ Mean (SD) or \% } & \\
\hline Age & $18.0(2.6)$ & $17.9(2.8)$ & $18.2(2.5)$ & $t(128)=.64$ \\
\hline Female & 16.0 & 12.7 & 20.0 & $x^{2}(1)=.81$ \\
\hline Institution & & & & \\
\hline Tactus & 25.2 & 19.7 & 31.7 & $x^{2}(3)=3.33$ \\
\hline Vincent van Gogh & 12.2 & 15.5 & 8.3 & \\
\hline Mondriaan & 29.8 & 31.0 & 28.3 & \\
\hline Novadic-Kentron & 32.8 & 31.7 & 33.8 & \\
\hline Living with (at least one) parent & 68.7 & 74.6 & 61.7 & $x^{2}(1)=1.98$ \\
\hline Higher education (high school or higher) & 50.4 & 47.9 & 53.3 & $x^{2}(1)=.19$ \\
\hline Having at least one non-Dutch parent & 19.1 & 16.9 & 21.7 & $x^{2}(1)=.22$ \\
\hline Cannabis use $(€)$ & $18.7(21.2)$ & $18.2(21.6)$ & $19.4(20.9)$ & $t(124)=.30$ \\
\hline Cannabis use sessions per week & $3.93(2.48)$ & $3.87(2.5)$ & $4.02(2.48)$ & $t(129)=.33$ \\
\hline Cigarettes per day & $9.4(7.6)$ & $9.6(7.3)$ & $9.2(7.9)$ & $t(127)=-.26$ \\
\hline Alcohol glasses per week & $11.5(14.6)$ & $8.9(12.2)$ & $14.6(16.6)$ & $t(129)=2.27^{*}$ \\
\hline Reported use of other drugs & 62.6 & 67.2 & 57.1 & $x^{2}(1)=.92$ \\
\hline Attitude & $3.03(.50)$ & $3.09(.51)$ & $2.97(.48)$ & $t(129)=-1.2$ \\
\hline Norm at baseline & $2.40(.62)$ & $2.38(.58)$ & $2.44(.67)$ & $t(128)=.54$ \\
\hline Perceived behavioral control & $2.98(1.14)$ & $2.94(1.19)$ & $3.02(1.08)$ & $t(129)=-.40$ \\
\hline
\end{tabular}

${ }^{*} p<0.05$ 
Table 2. Top-down multiple linear regression models for predicting change in SOC stages at post-test (T1) and at six-month follow-up (T2) by Moti-4.

\begin{tabular}{llccl}
\hline Dependent variable & $\mathrm{B}$ & Std. Error & $\mathrm{t}$ & $\mathrm{p}$ \\
\hline$\Delta$ stageT1 & & & & \\
Moti-4 & .91 & .133 & .712 & .486 \\
Age & .042 & .025 & 1.726 & .91 \\
$\Delta$ StageT2 & .238 & .167 & 1.212 & .155 \\
Moti-4 & .552 & .220 & 2.313 & $.011^{*}$ \\
Gender & .008 & .003 & 2.026 & $.016^{*}$ \\
Cannabis T0 & .012 & .005 & 1.942 & $.022^{*}$ \\
Alcohol T0 & .333 & .165 & 2.241 & $.049^{*}$ \\
Norm T0 & & & & \\
\hline
\end{tabular}

$p$-values are based on 5000 bootstrap samples; ${ }^{*} p<0.05 ;{ }^{* *} p<0.001$; $\Delta$ stage $11=$ change in stage at T1 compared to T0; $\Delta$ stageT2 = change in stage at T2 compared to T0. $\Delta$ tageT1ageT1 explained 58\% (Adj $\mathrm{R}^{2}=.58$ ) of the total variance of cannabis use, while at $\mathrm{T} 2$ the final models for change in stage between $\mathrm{T} 0$ and $\mathrm{T} 1$ and for change in stage between T0 and T2 explained $47 \%$ and $46 \%$, respectively $\left(\operatorname{AdjR}^{2}=0.47\right.$ and 0.46 , respectively). The summative interrelationships among these key variables are graphically represented by the path model in Figure 1.

Subsequently, three top-down multiple regressions assessed the influence of the change in stage between $\mathrm{T} 0$ and $\mathrm{T} 1$ and between $\mathrm{T} 0$ and $\mathrm{T} 2$ on cannabis consumption (Table 3). Stage of change was a significant predictor of a reduction of cannabis use at $\mathrm{T} 1$

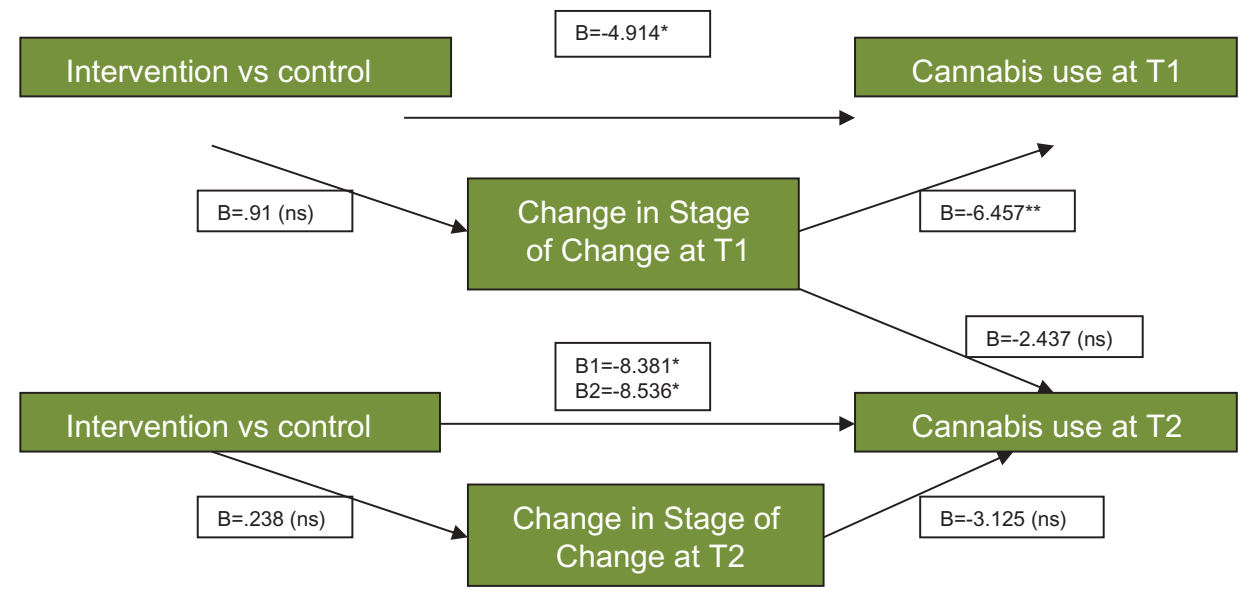

Figure 1. Path model of the relations among intervention, change in stage of change and cannabis use.

B: regression coefficient; ${ }^{*} p<.05 ;{ }^{* *} p<.001 ;$ ns = non-significant

$\mathrm{B} 1=$ regression coefficient in model with change in stage at $\mathrm{T} 1$ as predictor

$\mathrm{B} 2$ = regression coefficient in model with change in stage at $\mathrm{T} 2$ as predictor

Table 3. Top-down multiple linear regression models for predicting weekly cannabis use (expressed in euros) at post-test (T1) and at six month follow-up (T2) by change in SOC stage.

\begin{tabular}{|c|c|c|c|c|}
\hline Dependent variable & B & Std. Error & $\mathrm{t}$ & $p$ \\
\hline \multicolumn{5}{|c|}{ Cannabis use at T1 $(n=119)$} \\
\hline Moti-4 & -4.914 & 2.392 & -2.054 & $.043^{*}$ \\
\hline Gender & -8.197 & 3.249 & -2.523 & $.013^{*}$ \\
\hline Cannabis T0 & .580 & .060 & 9.673 & $.000^{* *}$ \\
\hline Behav. Cont. T0 & -2.169 & 1.123 & -1.932 & .056 \\
\hline$\Delta$ StageT1T0 & -6.457 & 1.787 & -3.613 & $.000^{* *}$ \\
\hline \multicolumn{5}{|c|}{ Cannabis use at T2 $(n=99)$} \\
\hline Moti-4 & -8.381 & 3.316 & -2.528 & $.013^{*}$ \\
\hline Gender & -14.002 & 4.475 & -3.129 & $.002^{*}$ \\
\hline Cannabis T0 & .517 & .085 & 6.118 & $.000^{* *}$ \\
\hline Norm T0 & 5.889 & 2.718 & 2.167 & $.033^{*}$ \\
\hline Behav. Cont. T0 & -2.721 & 1.571 & -1.732 & .087 \\
\hline Attitude T0 & 7.308 & 3.479 & 2.101 & $.039 *$ \\
\hline$\Delta$ Stage T1T0 & -2.437 & 2.486 & -.980 & .330 \\
\hline \multicolumn{5}{|c|}{ Cannabis use at T2 $(n=99)$} \\
\hline Moti-4 & -8.536 & 3.443 & -2.480 & $.015^{*}$ \\
\hline Gender & -12.479 & 4.769 & -2.616 & $.011^{*}$ \\
\hline Cannabis T0 & .579 & .085 & 6.783 & $.000^{* *}$ \\
\hline Norm T0 & 5.652 & 2.818 & 2.006 & $.048^{*}$ \\
\hline Attitude T0 & 6.381 & 3.595 & 1.775 & .080 \\
\hline$\Delta$ Stage T2T0 & -3.125 & 2.086 & -1.498 & .138 \\
\hline
\end{tabular}

${ }^{*} p<.05 ;{ }^{* *} p<.001$.

Final model at $\mathrm{T} 1$ : Adjusted $\mathrm{R}^{2}=.58$.

Final models at T2: Adjusted $R^{2}$ (for $\Delta$ StageT1T0) $=.47$, Adj $R^{2}($ for $\Delta$ StageT2T0) $=.46$ 
(regression coefficient $(\mathrm{B})=-6.46, p<0.001)$. After six months, however, stage of change (both at T1 and T2 compared to T0) was no longer a significant predictor of cannabis use. At T1, the final model explained 58\% (Adj $\mathrm{R}^{2}=.58$ ) of the total variance, while at $\mathrm{T} 2$ the final models explained $47 \%$ and $46 \%$, respectively (Adj $\mathrm{R}^{2}$ $\Delta \mathrm{T} 1=.47$; Adj $\left.\mathrm{R}^{2} \Delta \mathrm{T} 2=.46\right)$. Although change of stage significantly influences cannabis use at $\mathrm{T} 1$, none of the analyses revealed a significant effect of Moti- 4 on the change in the SOC stage. Hence, stage of change is neither a mediator for cannabis use at $\mathrm{T} 1$, nor for cannabis use at T2. In none of the complementary analyses was a significant effect found of Moti-4 on the change in scores on the Pre-contemplation, Contemplation, and Action subscales at T1 nor at T2. Linear regressions of the change in these scores showed that the change in score of the action subscale at posttest was a significant predictor of reducing one's cannabis use at T1 and T2 (T1: $\mathrm{B}=-3.97, p=.009$; T2: $\mathrm{B}=-5.37, p=.011)$. On the other hand, a higher score on pre-contemplation (at T1) and contemplation (at T1 and $\mathrm{T} 2$ ) led to a higher cannabis consumption.

\section{Discussion}

Our analysis of the scoring pattern on the RCQ was generally in line with the theoretical expectation of progression through the stages. The negative correlations of the $\mathrm{P}$ - with the $\mathrm{A}$ - and $\mathrm{C}$ - subscales at all measurement points suggest that pre-contemplation is a distinct phase that is negatively associated with the contemplation and action stages of change as contended by the TTM. Moreover, the moderate positive correlations that were found for the C- and A- subscales at $\mathrm{T} 0$ and $\mathrm{T} 1$ also provide evidence of a progressive change from a stage of pre-contemplation through contemplation to action. This is also in line with the TTM (McConnoughy et al. 1983). Two other validation studies (Defuentes-Merillas, De Jong, and Schippers 2002; Heather, Rollnick, and Bell 1993) reported similar, though slightly higher, values than our study. Further support for the TTM theory and SOC model is found after application of the cut-off point algorithm (Heather, Rollnick, and Bell 1993) used to define the specific stage of change. Together, these results demonstrate that the RCQ subscale scores and categorical profiles are useful for studies testing the SOC model in comparative effectiveness of intervention trials. However, our top-down regression analyses suggest that the criticism of the SOC model as theoretical explanation for the motivation for engagement and efficacy of MI-based interventions has some validity. The analyses demonstrate that there can be adverse effects in MI interventions associated with participants not moving quickly enough from the contemplation stage to the action stage. Treatment as usual (in this instance, brief counseling), as well as the MI based Moti-4, seem to have their adverse effects through a process of stimulating the participants' thinking more about their drug use without this being followed up promptly enough with nudges to action. Future research should focus on the optimal temporal sequence that MI intervention participants should remain in for each stage of change.

The second aim of our study concerned whether changes in stage attributed to the intervention would significantly predict the degree of change in the consumption of cannabis. A positive contribution of stage of change to the decrease in cannabis consumption was only found at T1. Only a small difference in regression coefficients and explained variance was found in the two models with or without SOC predictors. A joint significance test showed that the SOC variables mediate the effect of Moti-4 to some extent, but not enough to become statistically significant.

Our findings show the change in the score for the action stage at post-test to be a significant predictor of reduced cannabis use at $\mathrm{T} 1$ and $\mathrm{T} 2$. This implies that strengthening and promoting the participant's "action willingness" should be an important building block for interventions like Moti-4, and supports the contention that the SOC model offers one of the mechanisms accounting for behavioral change in adolescent cannabis users. Nevertheless, our findings also indicated that a higher score on "pre-contemplation" (at T1) and "contemplation" (at T1 and T2) predicted higher cannabis consumption. This leads to the disturbing conclusion that an MI intervention with an approach that keeps participants too long in the contemplative stage may do more harm than good. Important questions in this respect include how the ambivalence in adolescents differs from that in adults, and how the measurement of this ambivalence could be improved (Feldstein Ewing, Apodaca, and Gaume 2016). In practice, this means that more talking and thinking about cannabis (e.g., focus on reasons not to change), without an accompanying rapid nudge to action and a strategy for dealing with ambivalence, may lead to more rather than less cannabis. This has clinical significance in that the push towards evidence-based interventions is based on the recognition that many well-intentioned and theoretically sound interventions, without evidence from scientific testing, may have more disadvantages than benefits. Thus, a critically important clinical implication for the future improvement of the efficacy of Moti- 4 is 
to put less emphasis on contemplation and move as quickly as possible to a focus on how to increase action willingness. Another implication of our research is that just because a participant has motivation to continue to engage in a given treatment does not mean that the participant also wants to change behavior. This suggests that future studies of MI interventions should have a wider interest than just focusing on motivation for change, but also consider participants' motivation for engaging and retaining themselves in treatment even though there is no progression through the prescribed stages of change.

In our prior research (Dupont et al. 2015b) on Moti4, male participants and members of ethnic minorities were found to have reduced their cannabis use less than women and participants of Dutch origin. In this study, gender was also found to have a significant effect on SOC. At T2, girls are significantly more likely to show a positive change in SOC. Change in cannabis use by girls who participated in this study may be related to a change in their motivational structure. The reason for this needs further clarification. Cannabis users have been found to have both positive and negative beliefs about the effects of cannabis that influence the social norms regulating the prevalence and patterns of use. In this study, the perceived norm of what friends and parents think about cannabis use was significantly related to the level of use at the six-month follow-up. Recent Danish research showed strong associations between positive beliefs and norms and the continuation of cannabis use (Holm et al. 2014). Attempts to change the perceptions of social norms have been suggested as a strategy to reduce substance use by adolescents (Schultz et al. 2007). The significance of the influence of both youth and parental norm awareness found in our study suggests that changing the norms of adolescents might be more important than changing their motivation to change.

The findings of this study should be interpreted in the context of its limitations. The number of participants was relatively small. The small sample may explain the fact that the change in stage was not found to be a significant predictor of cannabis use at T2. Moreover, the data for our secondary analysis were drawn from an efficacy trial and therefore limited to multiple institutions located in a single geographical area. Different effects might have been found in larger cities in the Netherlands, such as Amsterdam and Rotterdam, where social norms and beliefs are known to be different than in the relatively rural south of the Netherlands, where this study was conducted. Finally, our analysis was restricted to the measures that were collected for the efficacy trial. Additional measures that have been found to be related to SOC could have been included if data collection was also oriented to testing the mechanism of Moti- 4 's efficacy.

While the SOC model does have some value in explaining the change in behavior that takes place in an MI intervention such as the Moti-4, alternative explanations for its efficacy have to be found elsewhere. One such alternative may be, for example, the quality of the therapeutic alliance. It has been estimated that about $30 \%$ of the outcome of interventions in addiction treatment is determined by the quality of the therapeutic alliance (Asay and Lambert 1999). Apart from raising the question of the mechanism of efficacy for MI interventions, our study also provides evidence that, along with a shift in focus and emphasis on action rather than contemplation within the intervention, the incorporation of a specific social norm element should also be considered as a useful additional component to enhance the present Moti-4 intervention. This could mean adding to the Moti-4 a specific emphasis on informing participants about the behavior of the majority of their peers and challenging their own normative expectations (Burchell, Rettie, and Patel 2013).

\section{References}

Apodaca, T. R., and R. Longabough. 2009. Mechanisms of change in motivational interviewing: A review and prelimary evaluation of the evidence. Addiction 104 (5):705-15. doi:10.1111/j.1360-0443.2009.02527.x.

Asay, T. P., and M. J. Lambert. 1999. The empirical case for the common factors in therapy: Quantitative findings. In The heart and soul of change: What works in therapy, ed. By M. A. Hubble, B. L. Duncan, and S. D. Miller, 23-55. Washington, DC: The American Psychological Association. Barnett, E., S. Sussman, C. Smith, L. A. Rohrbach, and D. Spruijt-Metz. 2012. Motivational interviewing for adolescent substance use: A review of the literature. Addictive Behaviors 37 (12):1325-34. doi:10.1016/j.addbeh.2012.07.001.

Bartholomew, L. K., G. S. Parcel, G. Kok, N. H. Gottlieb, and M. E. Fernandez. 2011. Planning health promotion programmes: An intervention mapping approach, 3rd ed. San Francisco, CA: Jossey-Bass.

Burchell, K., R. Rettie, and K. Patel. 2013. Marketing social norms: Social marketing and the social norm approach. Journal of Consumer Behavior 12:1-9. doi:10.1002/cb.1395.

Copeland, J., and W. Swift. 2009. Cannabis use disorder: Epidemiology and management. International Review of Psychiatry 21 (2):96-103. doi:10.1080/09540260902782745.

De Gee, E. A., J. E. E. Verdurmen, E. Bransen, J. M. De Jonge, and G. M. Schippers. 2014. A randomized controlled trial of a brief motivational enhancement for non-treatmentseeking adolescent cannabis users. Journal of Substance Abuse Treatment 47:181-88. doi:10.1016/j.sat.2014.05.001. 
De Jonge, J. M. 2005. Motivation for change in the addiction, studies in assessment. Groningen, the Netherlands: Rijksuniversiteit Groningen.

De Vet, E. 2005. Testing the transtheoretical model of behavior change: Validity and applicability for fruit intake. $\mathrm{Ph}$. D. dissertation, University of Maastricht, Nutrim Research School.

De Vries, H., E. Backbier, G. Kok, and M. Dijkstra. 1995. The impact of social influences in the context of attitude, selfefficacy, intention and previous behaviour as predictors of smoking onset. Journal of Applied Social Psychology 25:237-57. doi:10.1111/j.1559-1816.1995.tb01593.x.

De Weert-Van Oene, G. H., V. Gongora, K. Von Sternberg, and C. A. J. De Jong. 2015. Motivation for treatment and motivation for change in substance-dependent patients with co-occurring psychiatric disorders. Journal of Psychoactive Drugs 47:393-400. doi:10.1080/ 02791072.2015.1079669.

Defuentes-Merillas, L., C. A. I. De Jong, and G. M. Schippers. 2002. Reliability and validity of the Dutch version of the readiness to change questionnaire. Alcohol \& Alcoholism 37 (1):93-99. doi:10.1093/alcalc/37.1.93.

Degenhardt, L., and W. Hall. 2012. Extent of illicit drug use and dependence, and their contribution to the global burden of disease. The Lancet 379 (9810):55-70. doi:10.1016/ S0140-6736(11)61138-0.

Dupont, H. B., M. J. Candel, C. D. Kaplan, D. Van De Mheen, and N. K. De Vries. 2015b. Assessing the efficacy of Moti-4 for reducing the use of cannabis among youth in the Netherlands: A randomized controlled trial. Journal of Substance Abuse Treatment 65:6-12. doi:10.1016/j. jsat.2015.11.012.

Dupont, H. B., P. Lemmens, G. Adriana, D. Van De Mheen, and N. K. De Vries. 2015a. Developing the Moti-4 intervention, assessing its feasibility and pilot testing its effectiveness. BMC Public Health 15 (1):500. doi:10.1186/ s12889-015-1826-y.

EMCDDA. 2014. Annual report on the state of the drugs problem in Europe. Lisbon, Portugal: EMCDDA.

Etter, J. F., and S. Sutton. 2002. Assessing "stage of change" in current and former smokers. Addiction 97 (9):1171-82. doi:10.1046/j.1360-0443.2002.00198.x.

Evers, K. E., A. L. Paiva, J. L. Johnson, C. O. Cummins, J. O. Prochaska, J. M. Prochaska, J. Padula, and N. S. Gökbayrak. 2012. Results of a transtheoretical modelbased alcohol, tobacco and other drug intervention in middle schools. Addictive Behaviours 37:1009-18. doi:10.1016/j.addbeh.2012.04.008.

Feldstein Ewing, S. W., T. R. Apodaca, and J. Gaume. 2016. Ambivalence: Prerequisite for success in motivational interviewing with adolescents? Addiction 111 (11):1900-07. http://onlinelibrary.wiley.com/doi/10.1111/add.13286/pdf.

Field, A. 2009. Discovering statistics using SPSS, 3rd ed. London, England: Sage.

Fishbein, M., and I. Ajzen. 2010. Predicting and changing behaviour: The reasoned action approach. New York, NY: Taylor \& Francis.

Hall, W., and N. Solowij. 1998. The adverse effects of cannabis. The Lancet 352:1611-16. doi:10.1016/S0140-6736(98)05021-1.

Heather, N., S. Rollnick, and A. Bell. 1993. Predictive validity of the readiness to change questionnaire. Addiction 88:1667-77. doi:10.1111/add.1993.88.issue-12.
Henry, K. 2010. Skipping school and using drugs: A brief report. Drugs: Education, Prevention and Policy 17 (5):650-57.

Hibell, B., U. Guttormsson, S. Ahlström, O. Balakireva, T. Bjarnason, A. Kokkevi, and L. Kraus. 2012. The 2011 ESPAD report: Substance use among students in 36 European countries. Swedish Council for Information on Alcohol and Drugs (CAN). http://www.espad.org/ Uploads/ESPAD_reports/2011/The_2011_ESPAD_ Report_FULL_2012_10_29.pdf

Holm, S., S. Sandberg, T. Kolind, and M. Hesse. 2014. The importance of cannabis culture in young adult cannabis use. Journal of Substance Use 19 (3):251-56. doi:10.3109/ 14659891.2013.790493.

Horwood, L. J., D. M. Fergusson, M. R. Hayatbakhsh, J. M. Najman, C. Coffey, G. C. Patton, E. Silins, and D. M. Hutchinson. 2010. Cannabis use and educational achievement: Findings from three Australian cohort studies. Drug and Alcohol Dependence 110:247-53. doi:10.1016/j. drugalcdep.2010.03.008.

Kleinbaum, D. G., L. L. Kupper, and K. E. Muller. 1988. Applied regression and other multivariable methods. Belmont, CA: Duxbury Press.

Kuepper, R., J. Van Os, R. Lieb, H. U. Wittchen, M. Hofler, and C. Henquet. 2011. Continued cannabis use and risk of incidence persistence of psychotic symptoms: 10 year follow-up cohort study. BMJ 342:373. doi:10.1136/bmj.d738.

Lau, K., J. Freyer-Adam, B. Gaertner, H.-J. Rumpf, U. John, and U. Hapke. 2010. Motivation to change risky drinking and motivation to seek help for alcohol risk drinking among general hospital inpatients with problem drinking and alcohol-related diseases. General Hospital Psychiatry 32:86-93. doi:10.1016/j.genhosppsych.2009.10.002.

MacKinnon, D. P., C. M. Lockwood, J. M. Hoffman, S. G. West and V. Sheets. 2002. A comparison of methods to test mediation and other intervening variable effects. Psychological Methods 7 (1):83-104.

Madras, B. K., W. M. Compton, D. Avula, T. Stegbauer, J. B. Stein, and H. W. Clark. 2009. Screening, brief interventions, referral to treatment (SBIRT) for illicit drug and alcohol use at multiple healthcare sites: Comparison intake and 6 months later. Drug and Alcohol Dependence 99 (13):280-95. doi:10.1016/j.drugalcdep.2008.08.003.

Martin, G., and J. Copeland. 2008. The adolescent cannabis check-up: Randomized trial of a brief intervention for young cannabis users. Journal Substances Abuse Treatment 34:407-14. doi:10.1016/j.jsat.2007.07.004.

McConnoughy, E. A., C. C. Diclemente, J. O. Prochaska, and W. F. Velicer. 1983. Stages of change in psychotherapy: Measurement and sample profiles. Psychotherapy: Theory, Research and Practice 20:368-75. doi:10.1037/ h0090198.

Migneault, J. P., T. B. Adams, and J. P. Read. 2005. Application of the transtheoretical model to substance abuse: Historical development and future directions. Drug and Alcohol Review 24:437-48. doi:10.1080/09595230500290866

Miller, W. R., and S. Rollnick. 2012. Motivational interviewing, 3rd ed. New York, NY: Guilford Press.

Napper, L. E., M. M. Wood, A. Jaffe, D. G. Fisher, G. L. Reynolds, and J. A. Klahn. 2008. Convergent and discriminant validity of three measures of stage of change. Psychology of Addictive Behaviors 22:362-71. doi:10.1037/ 0893-164X.22.3.362. 
Pope, H. G., Jr., A. J. Gruber, J. I. Hudson, G. Cohane, M. A. Hustis, and D. Yurgelin-Todd. 2003. Early-onset cannabis use and cognitive deficits: What is the nature of the association? Drug and Alcohol Dependence 69:303-10. doi:10.1016/S0376-8716(02)00334-4.

Prochaska, J. O., and C. C. DiClemente. 1984. The transtheoretical approach: Crossing traditional boundaries of therapy. Homewood, IL: Dow Jones-Irwin.

Quinlan, K. B., and K. D. McCaul. 2000. Matched and mismatched interventions with young adult smokers: Testing a stage theory. Health Psychology 19 (2):165-71.

Riemsma, R. P., J. Pattenden, C. Bridle, A. J. Sowden, L. Mather, I. S. Watt, and A. Walker. 2002. A systematic review of the effectiveness of interventions based on a stages of change approach to promote individual behaviour change health. Health Technology Assessment 6:24. doi:10.3310/hta6240.

Rollnick, S., N. Heather, R. Gold, and W. Hall. 1992. Development of a short "Readiness to Change" Questionnaire for use in brief, opportunistic interventions among excessive drinkers. British Journal of Addiction 87:743-54. doi:10.1111/add.1992.87.issue-5.

Rooke, S., J. Copeland, M. Norberg, D. Hine, and J. McCambridge. 2013. Effectiveness of a self-guided, webbased cannabis treatment program: Randomized clinical trial. Journal of Medical Internet Research 15:2. doi:10.2196/ jmir.2256.

Ryan, R. M., and E. L. Deci. 2000. Self-determination theory and the facilitation of intrinsic motivation, social development, and well-being. American Psychologist 55:68-78. doi:10.1037/0003-066X.55.1.68.

Schippers, G. M. 2009. Motivatie tot behandeling en stadia van verandering [Motivation for treatment and stages of change]. In Handboek verslaving, ed. by I. Franken, and W. Van De Brink, 319-23. Utrecht, the Netherlands: de Tijdstroom.
Schultz, P. W., J. M. Nolan, R. B. Cialdini, N. J. Goldstein, and V. Griskevicius. 2007. The constructive, destructive, and reconstructive power of social norms. Psychological Science $18 \quad$ (5):429-34. doi:10.1111/j.14679280.2007.01917.x.

Snoek, A., E. Wits, and J. Van Der Stel. 2010. Kwetsbare groepen jeugdigen en (problematisch) middelengebruik: Visie en interventiematrix [Vulnerable groups and (problematic) alcohol and drug use: Vision and intervention matrix]. Rotterdam, the Netherlands: IVO. http://www. resultatenscoren.nl

Sussman, S., P. Sun, L. A. Rohrbach, and D. Spruijt-Metz. 2011. One year outcome of a drug abuse prevention program for older teens and emerging adults: Evaluating a motivational interviewing booster component. Health Psychology 31 (4):476-85. doi:10.1037/a0025756

Sutton, S. 2001. Back to the drawing board? A review of the applications of the transtheoretical model to substance use. Addiction 96:175-86. doi:10.1046/j.13600443.2001.96117513.x.

Van Laar, M. W., A. A. M. Cruts, M. M. J. Van OoyenHouben, R. F. Meijer, E. A. Croes, A. P. M. Ketelaars, J. E. E. Verdurmeen, and T. Brunt. 2015. Netherlands national drug monitor. Annual Report 2014, Trimbos Utrecht, Utrecht, the Netherlands.

Van Os, J., G. Kenis, and B. P. F. Rutten. 2010. The environment and schizophrenia. Nature 468:203-12. doi:10.1038/ nature 09563.

Van Sluis, M., M. Van Poppel, and W. Van Mechelen. 2004. Stage based lifestyle interventions in primary health care: Are they effective? American Journal of Preventive Medicine 26:330-43.

West, R. 2005. Time for a change: Putting the transtheoretical (stages of change) model to rest. Addiction 100:1036-39. doi:10.1111/j.1360-0443.2005.01139.x. 